\title{
Annual Bibliography For Publication In Technostyle
}

In every spring issue of the journal, Jennifer Connor, our former editor, always published an updated bibliography of administrative and technical communication in Canada. Included would be all articles, books or reviews published by Canadian scholars and, of course, all articles published in Technostyle or any other Canadian publication.

Anyone interested in contributing to the journal by compiling a yearly bibliography should contact:

Elenor Winter Friesen

Editorial Assistant

Department of Electrical \& Computer Engineering

University of Manitoba

Winnipeg, MB R3T 2N2

Ph: (204) 474-6469

Fax: (204) 275-0261

e-mail: ewinter@ee.umanitoba.ca

All CATTW members are encouraged to submit the titles of any recently published articles, books or reviews to the journal. 